\title{
Compliancy of Varied Diagonal angle pattern of Diagird tall buildings for Seismic Forces
}

\author{
Ramesh B M ${ }^{1}$, Dr. K Manjunatha ${ }^{2}$, Nikhil S Shastry ${ }^{3}$, \\ ${ }^{I}$ (Assistant Professor, Department of Civil Engineering, SJB Institute of Technology, Bengaluru, India) \\ ${ }_{2}^{2}$ (Professor, Department of Civil Engineering, UBDTCE, Davangere, India) \\ ${ }^{3}$ (PG Student, Department of Civil Engineering, SJB Institute of Technology, Bengaluru, India)
}

\begin{abstract}
Diagrid structural typology has its origin at the crossroads of architecture and engineering and has proved to be extremely compliant in structuring broad range of building forms and spans. The early applications of diagrid systems have not focused on exploring its potentials so much, hence a need for this issue is thus created. As a fact, buildings with regular geometry, evenly spread mass and stiffness in both plan and elevation; undergo lesser damage than buildings having irregular geometry. The diagrid module angle is a criterion which largely affects the structural performance, so under moderate to extreme earthquakes a characteristic seismic force battling system needs to be able to provide sufficient energy dissipation and ductility features. Since the existing works has focused only on constant diagonal angle throughout the building elevation a study on the variation in diagonal angle is taken up. In the present study diagrid building models having different variations in diagonal angle in the elevation are studied for their compliancy to fight seismic forces effectively. Models are simulated using ETABS software and analyzed in terms of Displacement, Storey shear, Storey stiffness, Storey drift, and Time period.
\end{abstract}

Keywords - Macro module, Top Storey Displacement, Storey shear, Storey Drift, Storey Stiffness, Time period.

\section{Introduction}

Notion of diagrid technology has subconsciously been aware with the characteristic firmness of triangular structures. Regular and oldest key in steel structures is location of diagonals, getting abundant fame among architects and engineers having extensive applications. But earlier architects enclosed diagonals inside the interior cores of buildings with a view that diagonals were highly obstructive. Whereas, the current scenario has a remarkable idea of using varied and multiple usage of triangulation which symbolizes the aesthetics of high-rise buildings.

In the year 2013 CCTV Headquarters located in Beijing China, won "The Best Tall Building" Worldwide from the Council on Tall Buildings and Urban Habitat. It is designated as a "3 Dimensional Cranked Loop" having an unfamiliar form with a height of $234 \mathrm{~m}$. Forming a continuous tube being bent at top and bottom with $90^{\circ}$ angle, whole building is fashioned by 2 inclined towers. The building uses an irregular diagrid system for its support primarily on the elevation which indicates a visual appearance of the forces drifting in the tubular structure. The bracing tube also provided the building sufficient strength for combating earthquake forces in the located place providing high safety level. The 2 towers were subjected to surface temperature variants owing to direct sunlight and independent move from wind before they were connected. It remained critical to examine the mode in which the structure acted in its partly built form and hence erection matters became a vital thought of the design procedure. The building allows the state-owned television newscaster to reach a fresh level of worldwide broadcasting, increasing its existing action of 13 channels up to 200 on finishing and associates managerial roles with broadcasting, news, programme production and studios.

The structural scheme was the outcome of an astonishing struggle by the Arup team and OMA as building with such type of eccentric loading and geometry had not been tried. Deprived of need of temporary support the diagrid was used as a share to allow the assembly of the huge multi-storey cantilevered sections of the tower. From the overall structural diagram it was visualized that the diagrid was incorporated over extra ordered framing scheme which included sloped column and beams. Depending on the loading pattern and density, diagonal system varies. The precise tasks fashioned by the form of this building surpassed the capacity of an interior core framed in steel and was not used to fight any lateral loading. Thus irregular modules used for such buildings that are highly angular ultimately appear chaotic. For such buildings to have the required shape the module size will be mapped carefully. In some instances where structural support is desired only for façade i.e. not fully glazed, the diagrid module tends not be conveyed in cladding. In such case module subdivisions are based on wind direction aspect and span distances of secondary supporting system rather on architectural concern to represent diagrid pattern in façade. 


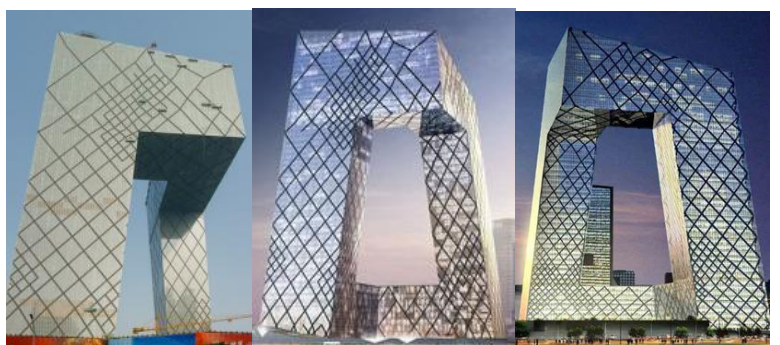

Fig:1 The CCTV Headquarters Building, Beijing, China

Irregular modules incline to possess more encounters when it comes to planning and structural design for the assembly and fabrication. Absence of modularity will make much distinctive geometry and hence diagrid technology has been even more critical to provision such kind of steel constructions. However, diagrids are emphasized on both interior and exterior form as they are visually driven.

A major reason for craze of diagrid is unquestionably the structural proficiency of triangulated designs in fact diagrid technology expresses an encouraging language of constancy, a message believable by its real physical economy and flexibility. The comparative studies carried out on diagrids with conventional buildings have proved that former has substantial stiffness, strength capability and amazing material economy than the latter.

As a result of integral monumentality of high-rise buildings with their huge mass, architectural manifestation becomes a momentous part in metropolitan context. Hence, within the existing urban environment creating high rise buildings requires a cautious investigation on aesthetic competence.

\section{Literature Review}

Of the available scientific literatures, only certain investigations have been developed principally for geometrically constant angled diagrids based on their performance assessment, design criteria and structural behaviour. Constant diagrids imply diagrid patterns having by the uniform diagonal angles of a triangle base unit, having constant geometrical qualities like height, scale, angle and width.

Authors Nishith B Panchal, Dr. V. R Patel, Dr. I. I. Pandya have examined the structural possibility of diagrids with alteration in angles and derived the optimal uniform angle of diagrids for 24, 36, 48 and 60 storied buildings with diagonals placed at various uniform angles in terms of top story displacement, story drift, and time period. Thus from the review it is found that the optimal angle of diagrid lies between 650 and 750 . Also authors have analyzed to what amount building height and diagonal angle criteria mark the design of diagrid structures and the necessity for story stiffness as factor has arisen particularly in the case of different diagonal angle of diagrids.

In particular Moon, suggests a stiffness-based methodology for initial structural design of diagrids. The parametric assignment of such technique to numerous building models, with different angle of diagonals, different number of stories, different share of shear flexibilities and bending, allows developing the optimal weight design solution.

Mele E, Brandonisio G, De Luca A a relative examination of the structural enactment of diagrid buildings branded by diverse elevations and geometries (the Swiss Re, Hearst and Guangzhou West towers), has been carried out. The results indicate that the acceptance of optimum module geometries, as proposed by Moon, permits for gaining precise efficient structural systems. It is also established that the strength necessities can be of supreme prominence in the sizing procedure of steel diagonal member.

Beginning from these interpretations the authors Montuori GM, Mele E, Brandonisio G, De Luca A have evaluated to what amount strength and stiffness measures distress the design of diagrids, uttering that, generally, it is not probable to forecast beforehand if overall member strength or stiffness demand will oversee the design. Hence both standards are needed and inevitable. Furthermore, design parameter, inters story drift as has arisen, principally in the circumstance of diagonals spanning numerous multiple stories. All these above mentioned investigation offerings deal with unvarying geometry diagrids, viz. designs with triangle base unit categorized by unvarying size and angle, in addition to the similar amount of base units accepted alongside the frontage elevation. In actual fact, the old-style method for accepting the variance of strength and stiffness needs, alongside the tall building elevation, contains altering the cross-sections or the steel strength of the structural members, while conserving the structure geometry, preserving column spacing in framed tubes, diagonal length in braced tubes, module scale, size and density in diagrid systems, etc.

Nonetheless, in the circumstance of diagrids, variable geometry schemes can also be implemented rendering to particular structural justifications, ensuing in varied geometrical designs categorized by scale, angle, size, density and depth of the base unit changing alongside the building frontages. Related cases of varied geometry diagrids originate after the constructions like the Lotte Super Tower structure, proposed by SOM, a 
diagrid having variant angle so as to enhance the participation of diagonal elements beside elevation in countering horizontal loads; the CCTV Headquarters has a diagrid with the base unit distinctively scaled through the building frontages for replying to deviations in native stresses, the schemes of the 1000 Museum building, in Miami, and of the Sunrise Tower, in Kuala Lumpur, both by Zaha Ha did, as well as the Hyper green tower intended by Jacques Ferrier, are only certain extra instances amid numerous applications of variable geometry diagrids.

Nevertheless, no study in the literature can be found on the compliancy of variable angle patterns for diagrid structures for fighting seismic forces for different parameters. Hence an effort has been made to find the most efficient optimal configuration of diagrid structures with variable diagonal angle. Specifically, 5 dissimilar diagonal angle patterns are simulated and assessed for 36 storey steel building model and checked for their compliancy for seismic parameters like maximum top storey displacement, maximum storey shear, maximum storey drift, maximum storey stiffness and time period. The resultant diagrid structures are evaluated and efficiency factors are estimated on the basis of analysis results and concluded with remarks.

\subsection{VARIABLE ANGLE DIAGRID CONFIGURATION}

"The shear stiffness claims and share of flexure in a diagrid building is a function of the building slenderness" is the strong justification behind the design approach implementing variable angle arrangements and it varies along elevation for a given building. It is probable that the supreme effective diagrid structures having solutions showing maximum stiffness to weight ratio must be categorized by variable angle alignments since the both the shear stiffness and bending of diagrid structure is strongly affected by module angle. It is anticipated that at the lower story levels the diagonal angle should be steep, where flexural stiffness claim is higher, than at upper levels, where shear stiffness demand usually prevails.

The structural enactment benchmarks for a diagrid system will differ for both high rise and low rise structures. Due to the activities of wind and potential earthquake occurrences high rise structures will have more lateral loads. The diagrid tube for a highly elevated building must behave like a vertical cantilever and remain extremely stiff and commonly speaking it has to fight shear forces in the top stories and moment forces near the base. The similar condition of severity of moment forces at the base circumstances is not present for low rise buildings that use diagrid system to provision floor loads.

So the module design for a tall building, suggests the structural requirement to have variation along the elevation of the building in compliancy for different lateral loading. Module design should consider increasing the member size on the floors at lower levels of the structure to house the gathering of gravity forces.

\section{A. Varied angle strategy: -}

First diagonal angle is obtained from ratio of height of module to the base width of module is modelled and analysed for seismic forces.

Diagonal angle $(\theta)=\operatorname{Tan}^{-1}$ (Height of module / base width)

Next, the building elevation is divided into piled macro-modules, having angle of diagrid constant inside every single macro module.

On the whole entire procedure is based on the determined optimal angle obtained in the uniform pattern as the median angle of the variable angle pattern from the literatures.

The building elevation is subdivided into stacking macro-modules, with diagrid angle kept constant within each macro module and increased going from the upper to the lowest macro modules. In the paper no specific formula is provided for defining the angle values in the macro modules.

For the last diagrid configuration, a special macro module is introduced in the middle portion of the elevation.

\section{B. Macro-modules considered: -}

5 different types of diagrid configurations are considered having different macro modules stacked together in the elevation. The different configurations with their stacked macro module considered are given in table. The configurations are Variant angle -1, Variant angle - 2, Variant angle - 3, Variant angle - 4, Variant angle - 5 .

For the first configuration Variant angle $-1,3$ macro modules are taken $50^{\circ}, 68^{0}$ and $75^{\circ}$. From storey 36 to storey 24 macro module $50^{\circ}$, from storey 24 to storey 12 macro module $68^{\circ}$ and from storey 12 to base macro module $75^{\circ}$.In the same way for remaining configurations macro modules are defined and given in table 1 and also shown in the figures. For the last configuration a special macro module of $50^{\circ}$ is introduced in the elevation in between diagrid modules as shown in the figure.

An elevated steel building model is considered for studying different configurations of the diagrid frontage, measuring the resultant effective geometrical properties and analysing the structural performance for fighting the seismic forces. The model has 36 storeys, with a square plot of $36 \mathrm{~m} \mathrm{X} 36 \mathrm{~m}$ and an inner core $12 \mathrm{~m} \mathrm{X} 12 \mathrm{~m}$. The total elevation of the building is $129.6 \mathrm{~m}$ with the storey height of $3.6 \mathrm{~m}$. The modelling and analysis is carried out using ETABS 2015. The dead load of the slab is $3.75 \mathrm{kN} / \mathrm{m}^{2}$ and the live load is $2.5 \mathrm{kN} / \mathrm{m}^{2}$. The 
design earthquake load is computed based on zone factor 0.16 , medium soil, importance factor 1 , and response reduction factor 5. The member sizes are shown in Table-1. Both linear static and response spectrum analysis has been carried out. The support conditions are taken as fixed.

\section{Model Geometry And Definition}

An elevated steel building model is considered for studying different configurations of the diagrid frontage, measuring the resultant effective geometrical properties and analysing the structural performance for fighting the seismic forces. The model has 36 storeys, with a square plot of $36 \mathrm{~m} \mathrm{X} \mathrm{36m} \mathrm{and} \mathrm{an} \mathrm{inner} \mathrm{core} 12 \mathrm{~m}$ $\mathrm{X} 12 \mathrm{~m}$. The total elevation of the building is $129.6 \mathrm{~m}$ with the storey height of $3.6 \mathrm{~m}$. The modelling and analysis is carried out using ETABS 2015. The dead load of the slab is $3.75 \mathrm{kN} / \mathrm{m} 2$ and the live load is $2.5 \mathrm{kN} / \mathrm{m} 2$. The design earthquake load is computed based on zone factor 0.16 , medium soil, importance factor 1 , and response reduction factor 5 . The member sizes are shown in Table-1.Both linear static and response spectrum analysis has been carried out. The support conditions are taken as fixed.

But in particular when 3 stacking modules in elevation is considered Variant angle-1 is efficient than Variant angle-2 in terms of all seismic parameters and when 2 stacking modules Variant angle-3 and Variant angle-4 are considered, Variant angle-3 is efficient because of the fact that with a steeper diagonal angle at the lower levels, bending stiffness demand is superior than at upper levels where shear stiffness requirement usually remains greater. And for Variant angle-5 all seismic parametric values resemble Variant angle-3.

\section{Figures And Tables}

To ensure a high-quality product, diagrams and lettering MUST be either computer-drafted or drawn using India ink. Figure captions appear below the figure, are flush left, and are in lower case letters. When referring to a figure in the body of the text, the abbreviation "Fig." is used. Figures should be numbered in the order they appear in the text.

Table captions appear centered above the table in upper and lower case letters. When referring to a table in the text, no abbreviation is used and "Table" is capitalized.

TABLE I. DIFFERENT DIAGRID CONFIGURATIONS CONSIDERED

\begin{tabular}{|c|l|}
\hline Diagrid Configuration & Macro module Angles (from top of elevation) \\
\hline Variant angle - 1 & $50^{0}, 68^{0}, 75^{0}$ \\
\hline Variant angle - 2 & $68^{0}, 78^{0}, 82^{0}$ \\
\hline Variant angle - 3 & $50^{0}, 68^{0}$ \\
\hline Variant angle - 4 & $68^{0}, 78^{0}$ \\
\hline Variant angle - 5 & $68^{0}, 50^{0}$ \\
\hline
\end{tabular}

TABLE II. MEMBER SIZES FOR THE MODEL CONSIDERED

\begin{tabular}{|c|c|c|c|}
\hline Member Type & Designation & Section & Remark \\
\hline \multirow{3}{*}{ Beams } & B1 & ISMB 550 & \multirow{2}{*}{ ISMB 600 with top and bottom plate } \\
\cline { 2 - 3 } & B2 & ISMB 600 & 25m thick \\
\cline { 2 - 3 } & B3 & ISMB550 & 2 I sections connected with 50mm plate \\
\hline Columns & C1 & 1500 X $1500 \mathrm{~mm}$ &
\end{tabular}

TABLE III. BUILT UP SECTION OF BEAM AND COLUMN

\begin{tabular}{|l|l|}
\hline Beam B2 & Column C1 \\
\hline & \\
\hline $\begin{array}{l}\text { ISMB } 600 \text { with top and } \\
\text { bottom plate 25mm thick }\end{array}$ & $\begin{array}{l}\text { I section depth } 1400 \mathrm{~mm}, \text { flanges } \\
\text { 400mm, web 40mm, plate 50mm }\end{array}$ \\
\hline
\end{tabular}




\section{TABLE IV. MAXIMUM TOP STOREY DISPLACEMENT}

\begin{tabular}{|c|c|c|}
\hline \multirow{2}{*}{ Type of Structure } & Linear Static & \multicolumn{2}{|c|}{$\begin{array}{c}\text { Response Spectrum } \\
\text { Resp / RespY } \\
\text { (mm) }\end{array}$} \\
\hline Variant Angle - 1 & $\begin{array}{c}\text { EQX / EQY } \\
\text { (mm) }\end{array}$ & 28 \\
\hline Variant Angle - 2 & 39 & 44 \\
\hline Variant Angle - 3 & 56 & 26 \\
\hline Variant Angle - 4 & 40 & 32 \\
\hline Variant Angle - 5 & 42 & 26 \\
\hline
\end{tabular}

TABLE V. STOREY SHEAR

\begin{tabular}{|c|c|c|}
\hline \multirow{2}{*}{ Type of Structure } & \multicolumn{2}{|c|}{ Storey Shear } \\
\cline { 2 - 3 } & Linear Static & Response Spectrum \\
\cline { 2 - 3 } & $\begin{array}{c}\text { EQX / EQY } \\
(\mathbf{k N})\end{array}$ & $\begin{array}{c}\text { RespX / RespY } \\
(\mathbf{k N})\end{array}$ \\
\hline Variant Angle - 1 & 3006 & 3006 \\
\hline Variant Angle - 2 & 2555 & 2555 \\
\hline Variant Angle - 3 & 3228 & 3228 \\
\hline Variant Angle - 4 & 2628 & 2628 \\
\hline Variant Angle - 5 & 3150 & 3150 \\
\hline
\end{tabular}

TABLE VI. MAXIMUM STOREY DRIFT

\begin{tabular}{|c|c|c|}
\hline \multirow{2}{*}{$\begin{array}{c}\text { Type of } \\
\text { Structure }\end{array}$} & \multicolumn{2}{|c|}{ Storey Drift } \\
\cline { 2 - 3 } & Linear Static & Response Spectrum \\
\cline { 2 - 3 } & $\begin{array}{c}\text { EQX / EQY } \\
(\mathbf{m})\end{array}$ & $\begin{array}{c}\text { RespX / RespY } \\
(\mathbf{m})\end{array}$ \\
\hline Variant Angle - 1 & 0.000387 & 0.0003 \\
\hline Variant Angle - 2 & 0.000688 & 0.000615 \\
\hline Variant Angle - 3 & 0.000372 & 0.000246 \\
\hline Variant Angle - 4 & 0.000469 & 0.000386 \\
\hline Variant Angle - 5 & 0.000408 & 0.000269 \\
\hline
\end{tabular}

TABLE VI. MAXIMUM STOREY STIFFNESS

\begin{tabular}{|c|c|c|}
\hline \multirow{2}{*}{ Type of Structure } & \multicolumn{2}{|c|}{ Storey Stiffness } \\
\cline { 2 - 3 } & Linear Static & Response Spectrum \\
\cline { 2 - 3 } & $\begin{array}{c}\text { EQX / EQY } \\
\text { (kN/m) }\end{array}$ & $\begin{array}{c}\text { RespX / RespY } \\
\text { (kN/m) }\end{array}$ \\
\hline Variant Angle - 1 & 8149128 & 8465875 \\
\hline Variant Angle - 2 & 3625248 & 3991250 \\
\hline Variant Angle - 3 & 11090489 & 11409313 \\
\hline Variant Angle - 4 & 5505727 & 5872507 \\
\hline Variant Angle - 5 & 11090822 & 11409618 \\
\hline
\end{tabular}

TABLE VII. TIME PERIOD

\begin{tabular}{|c|c|c|c|}
\hline \multirow{2}{*}{ Type of Structure } & \multicolumn{3}{|c|}{ Time period (sec) } \\
\cline { 2 - 4 } & $\mathbf{1}^{\text {st }}$ mode & 2nd mode & 3rd mode \\
\hline Variant Angle - 1 & 3.413 & 3.401 & 1.553 \\
\hline Variant Angle - 2 & 4.667 & 4.647 & 2.676 \\
\hline Variant Angle - 3 & 3.183 & 3.175 & 1.227 \\
\hline Variant Angle - 4 & 3.893 & 3.875 & 2.008 \\
\hline Variant Angle - 5 & 3.242 & 3.235 & 1.273 \\
\hline
\end{tabular}

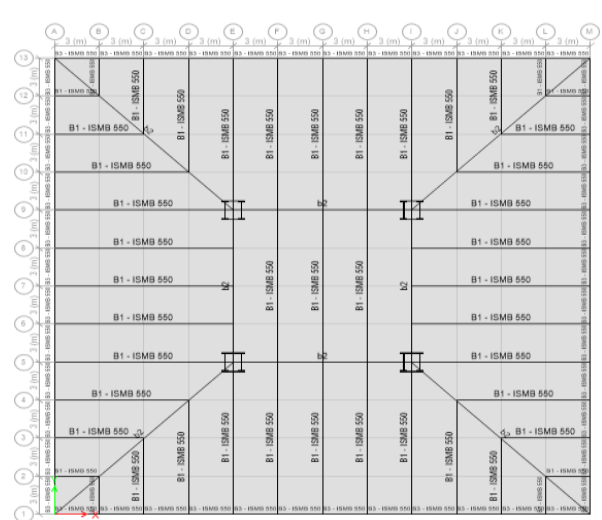

Fig 2: Plan of the 36 story Steel Building 


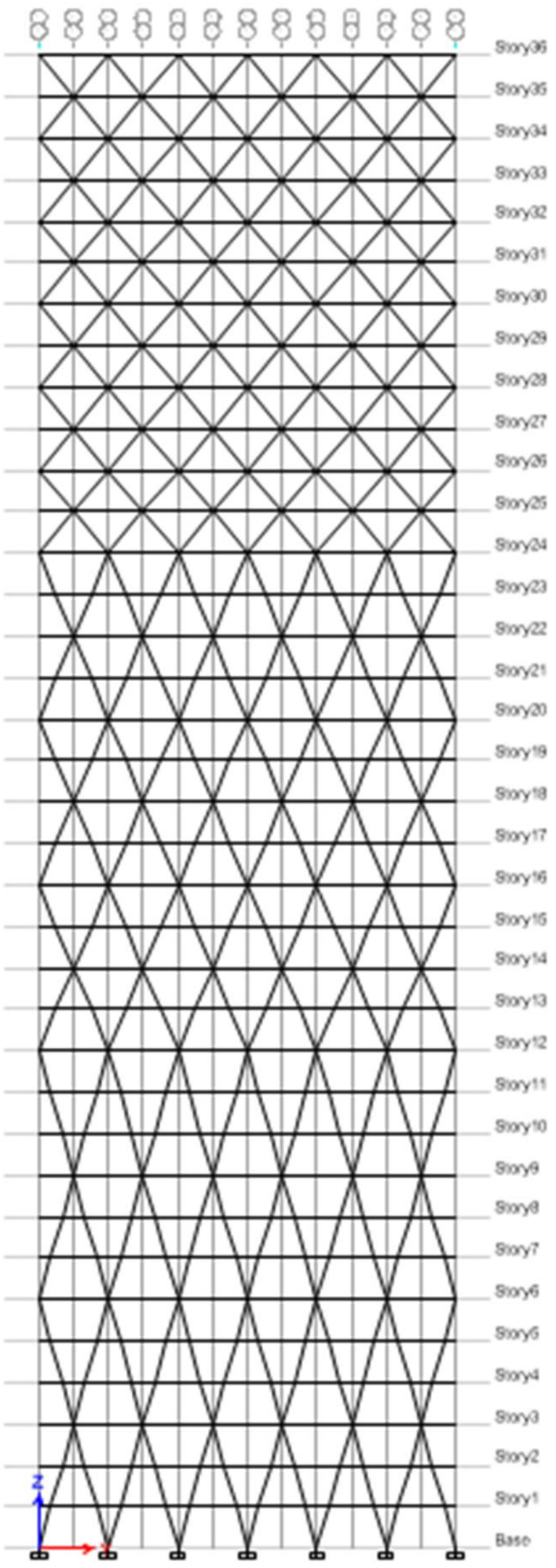

Fig3: Elevation of Variant angle-1 


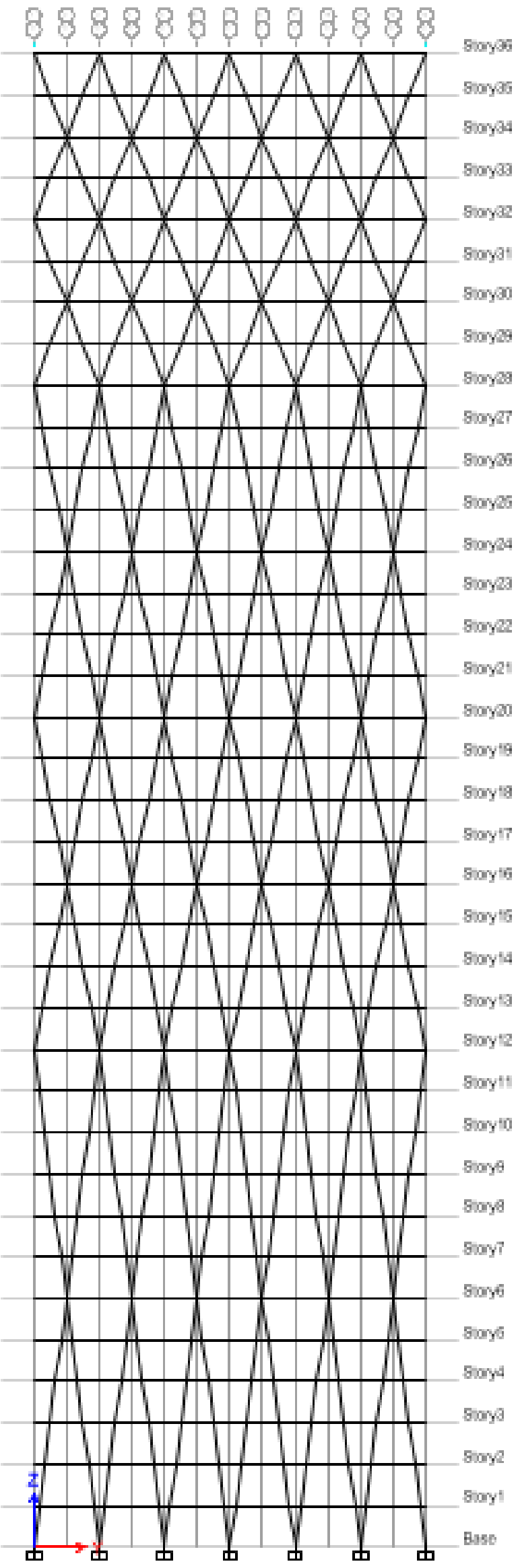

Fig4: Elevation of Variant angle-2 

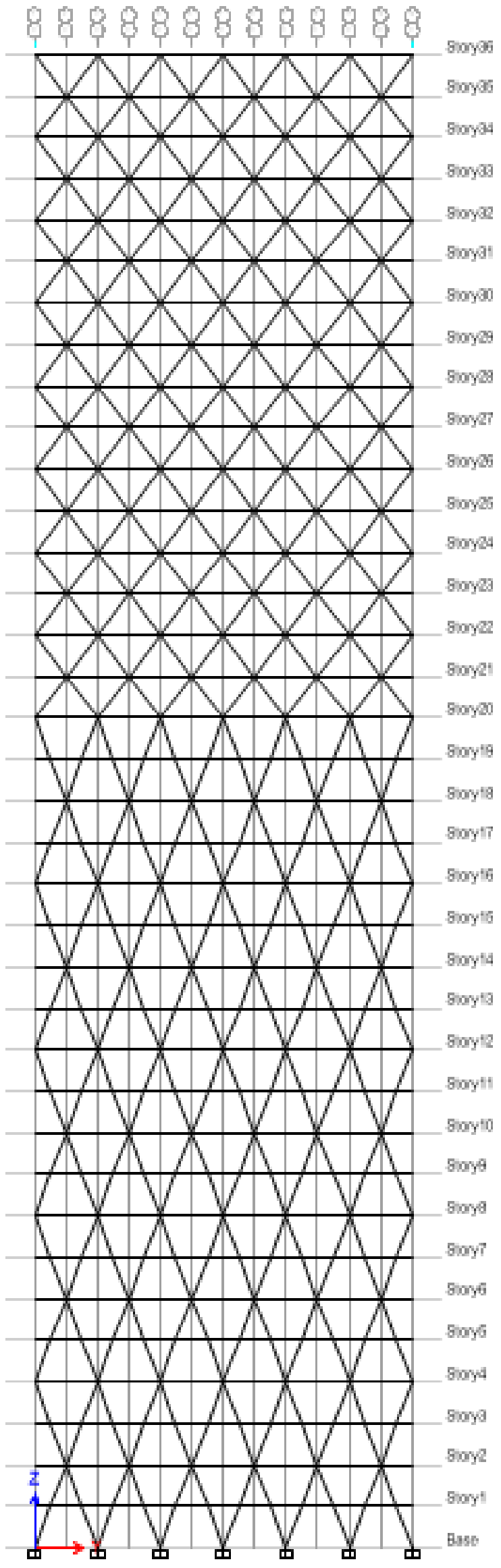

Fig5: Elevation of Variant angle-3 

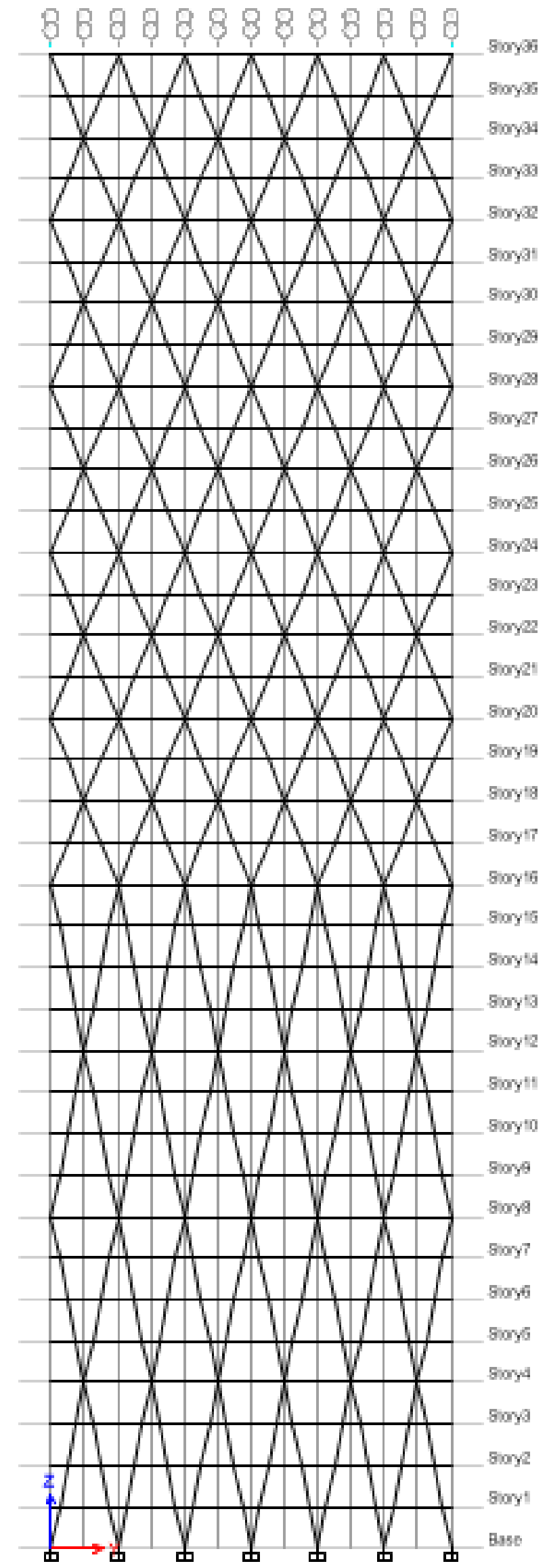

Fig6: Elevation of Variant angle-4 


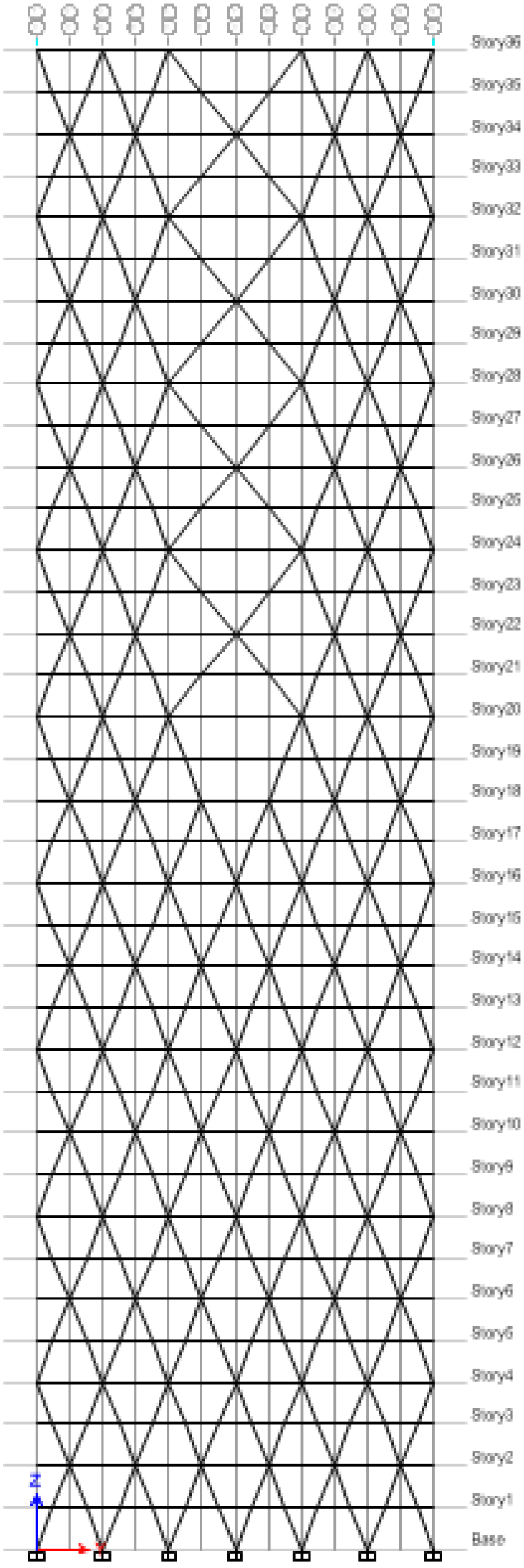

Fig7: Elevation of Variant angle-5 


\section{Conclusions}

Due to the absence of detailed survey on the compliancy of different variable angle diagrid patterns on fighting seismic forces, a research has been carried out on this issue which is under progress.

Here 5 different geometrical models of diagrid steel structures having 36 storey height with variable diagonal angle throughout the elevation is simulated in ETABS, analysed for various seismic parameters and commented.

$>$ The models, Variant angle-1 and Variant angle-3 are having similar top story displacement and stand better when compared to other considered configurations as the displacement value is lesser.

$>$ The model Variant angle-3 is having greater storey shear value compared to other generated models which implies that the system is capable of resisting more seismic forces.

$>$ In terms of storey drift Variant angle-3 gives lesser value when compared to other configurations and also remains within limit of $\mathrm{H} / 250$.

$>$ Both models Variant angle-3 and Variant angle-5 have similar stiffness compared to other generated configurations.

$>$ For the model Variant angle-3 the time period is lesser when compared to other configurations which imply that it has lesser mass and hence greater is the stiffness.

\section{References}

[1] Nishith B. Panchal, Dr. V. R. Patel, Dr. I. I. Pandya, “Optimum Angle of Diagrid Structural System”, Interanational Journal of Engineering and Technical Research (IJETR), ISSN: 2321-0869, Volume-2, Issue-6, June 2014

[2] Giovanni Maria Montuori, Elena Mele, Giuseppe Brandonisio and Antonello De Luca, "Geometrical patterns for diagrid buildings: Exploring alternative design strategies from the structural point of view," University of Naples Federico II, Department of Structures for Engineering and Architecture, Naples, Italy, pp. 112-127, April 2014.

[3] Mele E, Toreno M, Brandonisio G, De Luca A. Diagrid structures for tall buildings: case studies and design considerations. Struct Design Tall Spec Build 2014;23:124-45.

[4] Montuori GM, Mele E, Brandonisio G, De Luca A. Design criteria for diagrid tall buildings: stiffness versus strength. Struct Design Tall Spec Build 2013

[5] Moon KS. Sustainable structural engineering strategies for tall buildings. StructDes Tall Spec Build 2008;17(5):895-914.

[6] Moon KS. Optimal grid geometry of diagrid structures for tall buildings. ArchitSci Rev 2008;51(3):239-5.

[7] I.S. Jacobs and C.P. Bean, "Fine particles, thin films and exchange anisotropy," in Magnetism, vol. III, G.T. Rado and H. Suhl, Eds. New York: Academic, 1963, pp. 271-350.

[8] Moon KS, Connor JJ, Fernandez JE. Diagrid structural system for tall buildings:characteristics and methodology for preliminary design. Struct Des Tall SpecBuild 2007;16(2):205-30.

[9] Zhang C, Zhao F, Liu Y. Diagrid tube structures composed of straight diagonals with gradually varying angles. Struct Des Tall Spec Build 2012;21:283-95. G.M. Montuori et al./ Engineering Structures 71 (2014) 112-127 127 